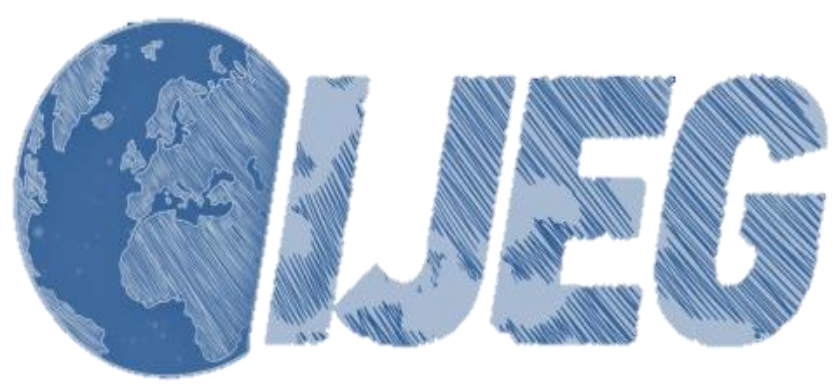

International Journal of Engineering and Geosciences (IJEG), Vol; 4, Issue; 1, pp. 026-032, February, 2020, ISSN 2548-0960, Turkey, DOI: 10.26833 ijeg.580373

\title{
INVESTIGATION OF THE CENTER COORDINATES OF A CIRCLE WITH UNKNOWN RADIUS USING POLAR MEASUREMENTS
}

\author{
Huseyin Ince ${ }^{1}$, Nuri Erdem 2* \\ ${ }^{1}$ Vocational School of Higher Education for Mapping and Land Survey, Hitit University, Çorum, Turkey, \\ (huseyinince@ hitit.edu.tr);ORCID 0000000161185502 \\ ${ }^{2 *}$ Engineering Faculty, Department of Geomatics Engineering, Osmaniye Korkut Ata University, Osmaniye, Turkey
} (nurierdem@ osmaniye.edu.tr); ORCID 0000-0002-1850-4616

*Corresponding Author, Received: 21/06/2019, Accepted: 28/08/2019

\begin{abstract}
Circular pools or buildings may be encountered in production of maps for making development plans, in the first facility cadaster and on land. Geodetic measurements may be made on at least three different points of the circleshaped pool or building to obtain positions in a coordinate system of measurement points with a geodetic ground-based electronic tachometer after connection to another polygon. It is possible to get a circle from these three points where the coordinates can be calculated, the coordinates of the center of the circle and the radius of the circle with the help of drawing programs (Netcad, Carto CAD, GEOCAD ...). In drawing programs related to cartography, the details of passing the circle from three points, the coordinates of the center of the circle and the radius of the circle cannot be accessed because the details are kept proprietary by software companies. We have been curious about how the coordinates of the center of the circle or the radius of the circle in question are calculated by using the subprograms on a computer. Apart from the information hidden by software companies, two studies which are indirectly close to the subject mentioned in the application have been identified with respect to the solution of the problem on the computer. However, it was found that these studies did not directly illuminate our research topic, so, this issue should be investigated. This study presents theoretical solutions for the topic, makes numerical implementations and provides findings and interpretations.
\end{abstract}

Keywords: Polar Coordinates, Coordinates Calculation, Polar Measurements, Circle Center Coordinate Calculation, Radius Calculation 


\section{INTRODUCTION}

Nowadays, in production of maps for construction of city and town development plans and in the first facility cadastral works, it is possible to encounter pools or buildings in circular form. After connecting to another polygon with an electronic tachometer installed at a polygon point installed in the field, the coordinates of the measurement points may be obtained by making geodetic measurements on at least three different points of the circular pool or building. With the help of drawing programs related to cartography (such as Netcad, Carto $\mathrm{CAD}$, GEOCAD ...), it is possible to obtain the coordinates of the center of a circle and the radius of this circle from these three points, the coordinates of which may also be calculated in the computer environment.

It is not possible to access this information in mapping programs for cartography because the details of passing an area from three points in a coordinate system, coordinates of the center of the circle and the radius of the circle are kept proprietary by software companies. We have been curious about how the coordinates of the center of a circle or the radius of the circle in question are calculated using the subprograms on a computer.

In relation to the solution of this problem, two studies that are indirectly close to the subject mentioned in practice have been identified (Kåsa, 1976; Coppe, 1993). However, it was found that these studies did not directly illuminate our research topic, so this issue should be investigated. Since no study was found in practice regarding the solution of this problem, it is necessary to investigate this problem. This study presents theoretical solutions for the topic, makes numerical implementations and provides findings and interpretations.

A new method is not proposed in this study. As the basic principle of the study, the passage of a circle through three points, the details of obtaining the coordinates and the radius of the center of the circle are intended to be clarified as they are kept secret by software companies.

In field studies related to cartography, it is always possible to encounter a drawing of a circular pool and a building in practice. Therefore, related software is used by practitioners. Since the content of other related software is kept confidential by the related commercial companies, it is not known what kind of problems exist in other software and calculations. In this study, theoretical solutions for the topic are presented, and numerical applications are provided.

The aim of this study is to determine the positions of three points on a circle with polar measurements made from a polygon point and find the coordinates of the circle's center and radius by taking advantage of geometric positions. After finding the coordinates of the points on the circle, the circle equation can be solved with the help of the coordinates of these points, and the coordinates of the center of the circle can be found in reference to the offset of indirect measures in the least squares method. However, such a solution takes a lot of time in comparison to the method mentioned in this study.

\section{CAlCUlation OF THE \\ COORDINATES OF MEASURING POINTS FROM A POLYGONAL POINT TO THREE-POINT POLAR MEASUREMENTS ON A CIRCLE}

In the vicinity of a circular pool or building, an electronic tachometer is installed at a previously established $\mathrm{P}_{1}$ polygon site, and a connection to another previously established $\mathrm{P}_{2}$ point is made. Three separate points $(\mathrm{A}, \mathrm{B}, \mathrm{C})$ are marked on the tracks near the pool or the floor of the building. Horizontal angles and horizontal distances $\left(\beta_{\mathrm{A}}, \beta_{\mathrm{B}}, \beta_{\mathrm{C}}, \mathrm{S}_{\mathrm{A}}, \mathrm{S}_{\mathrm{B}}, \mathrm{S}_{\mathrm{C}}\right)$ are measured by holding the marked point reflector (Figure 1).

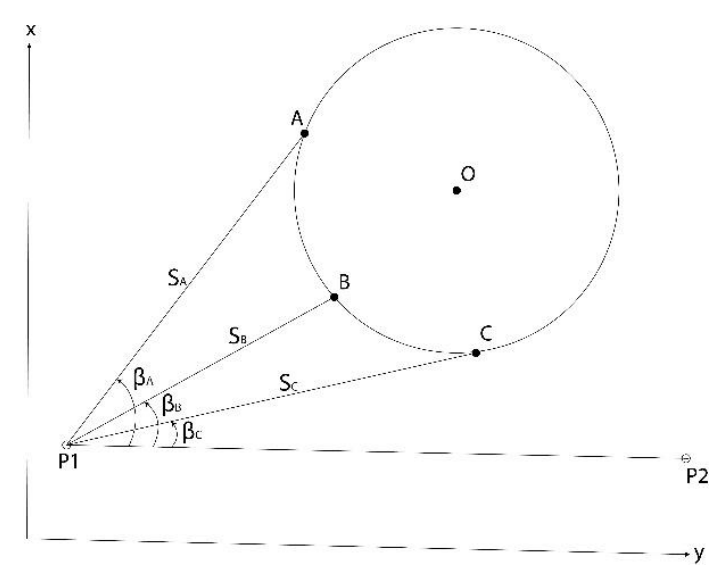

Figure 1: Measurement of points $\mathrm{A}, \mathrm{B}, \mathrm{C}$ with the electronic tachometer installed at point $\mathrm{P} 1$.

The coordinates of the points $\mathrm{A}, \mathrm{B}$ and $\mathrm{C}$ are calculated with the following relationships by using the coordinates of the stationary point and the connected points $\mathrm{P}_{1}$ and $\mathrm{P}_{2}\left(\mathrm{Y}_{1}, \mathrm{X}_{1}, \mathrm{Y}_{2}, \mathrm{X}_{2}\right.$ ) (Wolf and Ghilani, 2008; Ulvi and Toprak, 2016).

$\left(\mathrm{P}_{1} \mathrm{P}_{2}\right)=\arctan \left(\frac{\boldsymbol{Y}_{2}-\boldsymbol{Y}_{1}}{\boldsymbol{X}_{2}-\mathbf{1}}\right)$

$\left(\mathrm{P}_{1} \mathrm{~A}\right)=\left(\mathrm{P}_{1} \mathrm{P}_{2}\right)-\beta_{\mathrm{A}}$

$\left(\mathrm{P}_{1} \mathrm{~B}\right)=\left(\mathrm{P}_{1} \mathrm{P}_{2}\right)-\beta_{\mathrm{B}}$

$\left(\mathrm{P}_{1} \mathrm{C}\right)=\left(\mathrm{P}_{1} \mathrm{P}_{2}\right)-\beta_{\mathrm{C}}$

$\mathrm{Y}_{\mathrm{A}}=\mathrm{Y}_{1}+\mathrm{S}_{\mathrm{A}} * \sin \left(\mathrm{P}_{1} \mathrm{~A}\right), \mathrm{X}_{\mathrm{A}}=\mathrm{X}_{1}+\mathrm{S}_{\mathrm{A}} * \cos \left(\mathrm{P}_{1} \mathrm{~A}\right)$

$\mathrm{Y}_{\mathrm{B}}=\mathrm{Y}_{1}+\mathrm{S}_{\mathrm{B}} * \sin \left(\mathrm{P}_{1} \mathrm{~B}\right), \mathrm{X}_{\mathrm{B}}=\mathrm{X}_{1}+\mathrm{S}_{\mathrm{B}} * \cos \left(\mathrm{P}_{1} \mathrm{~B}\right)$

$\mathrm{Y}_{\mathrm{C}}=\mathrm{Y}_{1}+\mathrm{S}_{\mathrm{C}} * \sin \left(\mathrm{P}_{1} \mathrm{C}\right), \mathrm{X}_{\mathrm{C}}=\mathrm{X}_{1}+\mathrm{S}_{\mathrm{C}} * \cos \left(\mathrm{P}_{1} \mathrm{C}\right)$

The $\mathrm{AB}$ and $\mathrm{BC}$ chord lengths are found from the following relations;

$\mathrm{AB}=\sqrt{\left(Y_{B}-Y_{A}\right)^{2}+\left(X_{B}-X_{A}\right)^{2}}$
$\mathrm{BC}=\sqrt{\left(Y_{C}-Y_{B}\right)^{2}+\left(X_{C}-X_{B}\right)^{2}}$

The fourth point can also be marked and measured to check the traces of the circular pool or building near the ground. In this case, the horizontal angle and horizontal distances measured for the fourth point are used in the relations formed similar to the relations above, the coordinate of the fourth point and the beam length between the nearest measuring point can be calculated. 


\section{CALCULATION OF THE CENTER COORDINATES AND RADIUS OF A CIRCLE WITH CHORD POINTS}

The chord points may be marked on the circle as equal or different chord lengths.

3.1. Calculation of the Center Coordinates and Radius of a Circle with Points Marked on Equal Chord Lengths

If the chord lengths at the points on the circle are equal to each other $(\mathrm{AB}=\mathrm{BC})($ Fig. 2), then the angles of the base at points $A, B$ and $C(\alpha)$ in the isosceles triangles formed in the circle will be equal to each other.

The angles $\alpha$ and $\varepsilon$ are obtained from the following relations (Allan et al., 1968; Anderson and Mikhail, 1998; Kavanagh, 2000; Kavanagh, 2003; Kavanagh, 2009; İnce and Erdem, 2019).

$$
\begin{aligned}
& (\mathrm{BC})=\arctan \left(\frac{\boldsymbol{Y}_{C}-\boldsymbol{Y}_{B}}{\boldsymbol{X}_{C}-\boldsymbol{X}_{B}}\right) \\
& (\mathrm{BA})=\arctan \left(\frac{\boldsymbol{Y}_{A}-\boldsymbol{Y}_{B}}{\boldsymbol{X}_{A}-\boldsymbol{X}_{B}}\right) \\
& \alpha=\frac{(\boldsymbol{B C})-(\boldsymbol{B A})}{2} \\
& \varepsilon=200-2 \alpha
\end{aligned}
$$

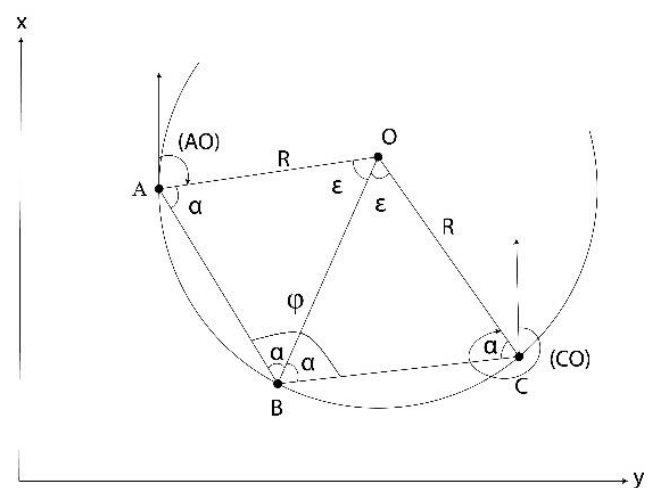

Figure 2: Radius (R) account with the dots marked at equal chord lengths.

In Figure 2, $\mathrm{R}=\mathrm{AO}=\mathrm{BO}=\mathrm{CO}$ is found with the following relations;

$\mathrm{AO}=\frac{A B \sin \alpha}{\sin \varepsilon}$
$\mathrm{BO}=\frac{B C \sin \alpha}{\sin \varepsilon}$

The bearing angles ((AO), (BO), and $(\mathrm{CO}))$ are obtained from the following equations from the points $\mathrm{A}$, $\mathrm{B}$ and $\mathrm{C}$ to point $\mathrm{O}$;

$(\mathrm{AB})=(\mathrm{BA}) \pm 200^{\mathrm{g}}$

$(\mathrm{CB})=(\mathrm{BC}) \pm 200^{\mathrm{g}}$

$(\mathrm{AO})=(\mathrm{AB})-\alpha$

$(\mathrm{BO})=(\mathrm{BA})+\alpha=(\mathrm{BC})-\alpha$

$(\mathrm{CO})=(\mathrm{CB})+\alpha$

The coordinates of the center of the circle (YO, XO) are derived from the following relations;

$\mathrm{A} \rightarrow \mathrm{Y}_{\mathrm{O}}=\mathrm{Y}_{\mathrm{A}}+\mathrm{R} \sin (\mathrm{AO}), \mathrm{X}_{\mathrm{O}}=\mathrm{X}_{\mathrm{A}}+\mathrm{R} \cos (\mathrm{AO})$

$\mathrm{B} \rightarrow \mathrm{Y}_{\mathrm{O}}=\mathrm{Y}_{\mathrm{B}}+\mathrm{R} \sin (\mathrm{BO}), \mathrm{X}_{\mathrm{O}}=\mathrm{X}_{\mathrm{B}}+\mathrm{R} \cos (\mathrm{BO})$

$\mathrm{C} \rightarrow \mathrm{Y}_{\mathrm{O}}=\mathrm{Y}_{\mathrm{C}}+\mathrm{R} \sin (\mathrm{CO}), \mathrm{X}_{\mathrm{O}}=\mathrm{X}_{\mathrm{C}}+\mathrm{R} \cos (\mathrm{CO})$
(Bannister et al., 1992; Bannister et al., 1998, Erdem and İnce, 2016)

3.2. Calculation of the Center Coordinates and Radius of a Circle with Points Marked on Different Chord Lengths

If the chord lengths between the points marked on the circle are different, then the base angles $\left(\alpha_{1}, \alpha_{2}\right)$ in the $\mathrm{OAB}$ and $\mathrm{OBC}$ triangles are not equal to each other. In Fig. 3, the angle $(\varphi)$ between the BA and BC chords at point $B$ and $\alpha_{1}$ are expressed by the following relations (Kavanagh and Bird, 2000; Kavanagh, 2003; Kavanagh, 2009);

$$
\begin{aligned}
& \varphi=(\mathrm{BC})-(\mathrm{BA}) \\
& \alpha_{2}=\varphi-\alpha_{1}
\end{aligned}
$$

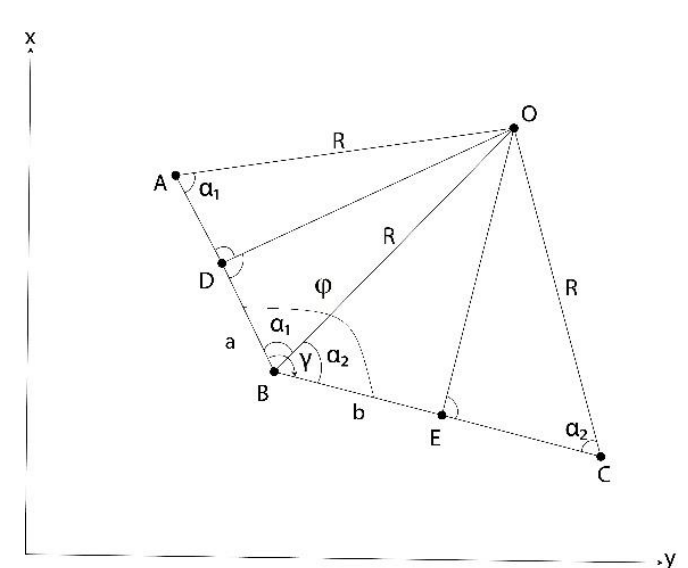

Figure 3: Radius (R) account with the points marked on different chord lengths.

In Fig. 3;

$a=A B / 2$

$\mathrm{b}=\mathrm{BC} / 2$

$D$ : the midpoint of the $\mathrm{AB}$ chord, $\mathrm{E}$ : the midpoint of the $\mathrm{BC}$ chord, and the following equation is written for $\mathrm{R}$ in the right triangles of ODB and OBE.

$\mathrm{R}=\frac{a}{\cos \alpha_{1}}=\frac{b}{\cos \left(\varphi-\alpha_{1}\right)}$

$\mathrm{a} \cos \left(\varphi-\alpha_{1}\right)=\mathrm{b} \cos \alpha_{1}$

The $\cos \left(\varphi-\alpha_{1}\right)$ equation is explained, and as a result of the necessary simplification, $\alpha_{1}$ is expressed as follows:

$\alpha_{1}=\arccos \left(\frac{a \sin \varphi}{\sqrt{\left((a \cos \varphi-b)^{2}+(a \sin \varphi)^{2}\right)}}\right)$

$\alpha_{1}$, which is calculated by the equation (30) is substituted at the bond (28) to obtain R. $\alpha_{1}$ is substituted in the relation (25), and $\alpha_{2}$ is calculated. (AO), (BO) and $(\mathrm{CO})$, which contain the points $\mathrm{O}, \mathrm{A}$ and $\mathrm{B}$, and $\mathrm{C}$ are obtained from the following equations;

$(\mathrm{AO})=(\mathrm{AB})-\alpha_{1}$

$(\mathrm{BO})=(\mathrm{BA})+\alpha_{1}$

$(\mathrm{BO})=(\mathrm{BC})-\alpha_{2}$

$(\mathrm{CO})=(\mathrm{CB})+\alpha_{2}$

The coordinates of the center of the circle $\left(\mathrm{Y}_{\mathrm{O}}, \mathrm{X}_{\mathrm{O}}\right)$ are obtained from the points A, B and C by the relations (21), (22) and (23) (Wilfred, 2001; Wolf and Ghilani, 2008). 
The fourth point in equal spacing can also be measured on the traces of the circular pool or building near the ground for control purposes. In this case, the calculated coordinates of the fourth point as defined in the first section and the correlations formed similar to the one above are used, and the coordinates of the circle center $\mathrm{O}$ and the radius of the circle can be calculated. If significant differences are observed in the calculation results, the measurements and calculations are repeated. If there are small differences $(1-2 \mathrm{~cm})$ between the results, the results that are obtained are averaged.
Numerical Implementation 1:

The points $\mathrm{A}, \mathrm{B}$ and $\mathrm{C}$ are marked on the same radius of $5.00 \mathrm{~m}$ chord lengths on a circle with an unknown radius shown in Figure 1. These points are measured by the polar method with connection to the point $\mathrm{P}_{2}$ by an electronic tachometer installed at the point $\mathrm{P}_{1}$. Using the given measurements and the coordinates of the polygon points given in Table 1 , we calculate the coordinates of the marked points of $\mathrm{A}, \mathrm{B}$ and $\mathrm{C}$, the radius of the pool and the coordinates of the center of the pool.

\section{NUMERICAL IMPLEMENTATIONS}

Table 1- Coordinates of polar coordinates and polygons made from point $\mathrm{P}_{1}$

\begin{tabular}{|l|l|l|l|l|c|}
\hline $\begin{array}{c}\text { Station } \\
\text { number }\end{array}$ & $\begin{array}{c}\text { Number of points of } \\
\text { observation }\end{array}$ & $\begin{array}{c}\text { Horizontal } \\
\text { Angle }\end{array}$ & $\begin{array}{c}\text { Horizontal } \\
\text { Distance }\end{array}$ & $\mathrm{Y}$ & $\mathrm{X}$ \\
\hline $\mathrm{P}_{1}$ & & & & 8210.227 & 7215.475 \\
\hline & $\mathrm{P}_{2}$ & 0.0000 & & 8560.735 & 7225.608 \\
\hline & $\mathrm{A}$ & 25.9550 & 83.065 & & \\
\hline & $\mathrm{B}$ & 23.0359 & 86.219 & & \\
\hline & $\mathrm{C}$ & 21.8019 & 90.915 & & \\
\hline
\end{tabular}

Solution;

$\Delta \mathrm{Y}_{\mathrm{P} 1 \mathrm{P} 2}=350.508 \mathrm{~m} ., \Delta \mathrm{X}_{\mathrm{P} 1 \mathrm{P} 2}=10.133 \mathrm{~m} ., \quad\left(\mathrm{P}_{1} \mathrm{P}_{2}\right)=$ $\arctan \left(\frac{\mathbf{3 5 0 . 5 0 8}}{\mathbf{1 0 . 1 3 3}}\right)=98^{\mathrm{g}} .1601$

$\beta_{\mathrm{A}}=25^{\mathrm{g}} .9550, \beta_{\mathrm{B}}=23^{\mathrm{g}} .0359, \beta_{\mathrm{C}}=21^{\mathrm{g}} .8019, \mathrm{~S}_{\mathrm{A}}=83.065$

$\mathrm{m} ., \mathrm{S}_{\mathrm{B}}=86.219 \mathrm{~m} ., \mathrm{S}_{\mathrm{C}}=90.915 \mathrm{~m}$.

The angles of the points that are required to obtain the coordinates of the points $\mathrm{A}, \mathrm{B}$ and $\mathrm{C}$ from the point $\mathrm{P} 1$ are obtained from the following equations.

$\left(\mathrm{P}_{1} \mathrm{~A}\right)=\left(\mathrm{P}_{1} \mathrm{P}_{2}\right)-\beta_{\mathrm{A}}=72^{\mathrm{g}} .2051,\left(\mathrm{P}_{1} \mathrm{~B}\right)=\left(\mathrm{P}_{1} \mathrm{P}_{2}\right)-\beta_{\mathrm{B}}=75$ g.1242 and

$\left(\mathrm{P}_{1} \mathrm{C}\right)=\left(\mathrm{P}_{1} \mathrm{P}_{2}\right)-\beta_{\mathrm{C}}=76^{\mathrm{g}} .3582$

Using the equations (5), (6) and (7), the coordinates of the points $\mathrm{A}, \mathrm{B}$ and $\mathrm{C}$ are obtained.

$\mathrm{Y}_{\mathrm{A}}=8285.500 \mathrm{~m} ., \mathrm{XA}=7250.600 \mathrm{~m}$.

$\mathrm{Y}_{\mathrm{B}}=8289.947 \mathrm{~m} ., \mathrm{XB}=7248.314 \mathrm{~m}$.

$\mathrm{Y}_{\mathrm{C}}=8294.945 \mathrm{~m} ., \mathrm{XC}=7248.467 \mathrm{~m}$.

$(\mathrm{BA})=400-\arctan \left(\frac{\mathbf{4 . 4 4 7}}{\mathbf{2 . 2 8 6}}\right)=330^{\mathrm{g}} .2285$

$(\mathrm{BC})=\arctan \left(\frac{\mathbf{4 . 9 9 8}}{\mathbf{0 . 1 5 3}}\right)=98^{\mathrm{g}} .0518$

The $\mathrm{AB}$ and $\mathrm{BC}$ chord lengths are obtained from the following equations (7) and (8).

$\mathrm{AB}=5.000 \mathrm{~m}$., $\mathrm{BC}=5.000 \mathrm{~m}$.

$\alpha=\frac{(\boldsymbol{B C})-(\boldsymbol{B A})}{2}=83^{\mathrm{g}} .9116, \mathrm{R}=\frac{2.5}{\cos \alpha}=9.9986 \mathrm{~m} . \approx 10.00 \mathrm{~m}$.

The bearing angles from $\mathrm{A}, \mathrm{B}$ and $\mathrm{C}$ to the center point $\mathrm{O}$ are obtained from the following equations.

$(\mathrm{AO})=(\mathrm{AB})-\alpha=46^{\mathrm{g}} .3169,(\mathrm{BO})=(\mathrm{BC})-\alpha=14^{\mathrm{g}} .1302$, $(\mathrm{CO})=(\mathrm{CB})+\alpha=381^{\mathrm{g}} .9634$

Using the equations (21), (22) and (23), the coordinates of the center $\mathrm{O}$ are obtained as follows.

$\mathrm{A} \rightarrow \mathrm{Y}_{\mathrm{O}}=8292.150 \mathrm{~m} ., \mathrm{X}_{\mathrm{O}}=7258.068 \mathrm{~m}$.

$\mathrm{B} \rightarrow \mathrm{Y}_{\mathrm{O}}=8292.148 \mathrm{~m} ., \mathrm{X}_{\mathrm{O}}=7258.069 \mathrm{~m}$.

$\mathrm{C} \rightarrow \mathrm{Y}_{\mathrm{O}}=8292.150 \mathrm{~m}$., $\mathrm{X}_{\mathrm{O}}=7258.068 \mathrm{~m}$.

The exact coordinates of $\mathrm{O}: \mathrm{Y}_{\mathrm{O}}=8292.149 \mathrm{~m} ., \mathrm{X}_{\mathrm{O}}=$ $7252.068 \mathrm{~m}$.
Numerical Implementation 2:

The points $\mathrm{A}, \mathrm{B}$ and $\mathrm{C}$ are marked on the chord lengths of $5.00 \mathrm{~m}$. and $8.00 \mathrm{~m}$. on a circle-shaped pool with an unknown radius as shown in Fig. 4. These points are measured by the polar method with connection to the point $\mathrm{P}_{2}$ by an electronic tachometer installed at the point $\mathrm{P}_{1}$. Using the given measurements and the coordinates of the polygon points given in Table 2 , we calculate the coordinates of the marked points $\mathrm{A}, \mathrm{B}$ and $\mathrm{C}$, the radius of the pool and the coordinates of the center of the pool.

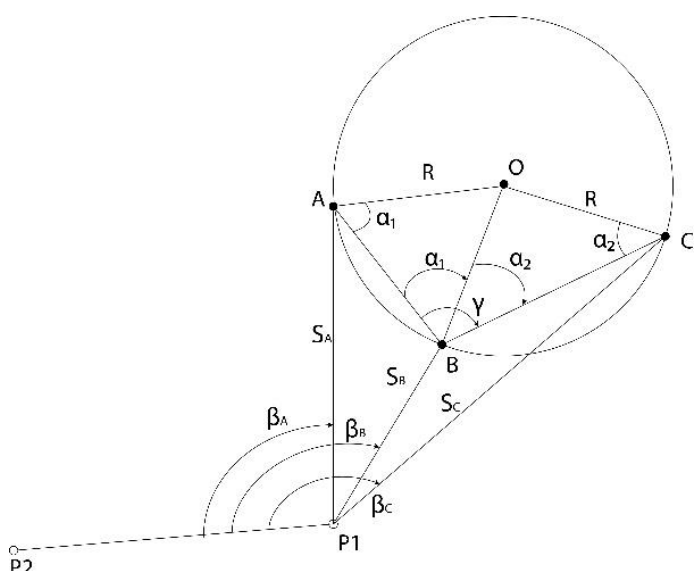

Figure 4: A pool with an unknown radius. 
Table 2- Coordinates of polar coordinates and polygons made from point $\mathrm{P}_{1}$

\begin{tabular}{|c|c|c|c|c|c|}
\hline $\begin{array}{c}\text { Station } \\
\text { number }\end{array}$ & $\begin{array}{c}\text { Number of points } \\
\text { of observation }\end{array}$ & $\begin{array}{c}\text { Horizontal } \\
\text { angle }\end{array}$ & $\begin{array}{c}\text { Horizontal } \\
\text { Distance }\end{array}$ & $\mathrm{Y}$ & $\mathrm{X}$ \\
\hline $\mathrm{P}_{1}$ & & & & 7802.318 & 5335.972 \\
\hline & $\mathrm{P}_{2}$ & 0.0000 & & 7595.612 & 5230.674 \\
\hline & $\mathrm{A}$ & 187.8733 & 83.065 & 64.192 & \\
\hline & $\mathrm{B}$ & 191.9292 & 86.219 & 66.943 & \\
\hline & $\mathrm{C}$ & 195.3468 & 90.915 & 73.995 & \\
\hline
\end{tabular}

Solution;

$\left(\mathrm{P}_{1} \mathrm{P}_{2}\right)=200+\arctan \left(\frac{\mathbf{2 0 6 . 7 0 6}}{\mathbf{1 0 5 . 2 9 8}}\right)=270^{\mathrm{g}} .0059$

$\beta_{\mathrm{A}}=187^{\mathrm{g}} .8733, \beta_{\mathrm{B}}=191^{\mathrm{g}} .9292, \beta_{\mathrm{C}}=195^{\mathrm{g}} .3468, \quad \mathrm{~S}_{\mathrm{A}}=$ $64.192 \mathrm{~m} ., \mathrm{S}_{\mathrm{B}}=66.943 \mathrm{~m}$. and

$\mathrm{S}_{\mathrm{C}}=73.995 \mathrm{~m}$.

The angles of the points that are required to obtain the coordinates of the points $\mathrm{A}, \mathrm{B}$ and $\mathrm{C}$ from the point $\mathrm{P} 1$ are obtained from the following equations.

$\left(\mathrm{P}_{1} \mathrm{~A}\right)=\left(\mathrm{P}_{1} \mathrm{P}_{2}\right)+\beta_{\mathrm{A}}-400=5^{\mathrm{g}} .8792,\left(\mathrm{P}_{1} \mathrm{~B}\right)=\left(\mathrm{P}_{1} \mathrm{P}_{2}\right)+\beta_{\mathrm{B}}$ $-400=61^{\mathrm{g}} .9351$,

$\left(\mathrm{P}_{1} \mathrm{C}\right)=\left(\mathrm{P}_{1} \mathrm{P}_{2}\right)+\beta_{\mathrm{C}}-400=65^{\mathrm{g}} .3527$

Using the equations (5), (6) and (7), the coordinates of the points $\mathrm{A}, \mathrm{B}$ and $\mathrm{C}$ are obtained.

$\mathrm{Y}_{\mathrm{A}}=7852.965 \mathrm{~m} ., \mathrm{X}_{\mathrm{A}}=5375.412 \mathrm{~m}$.

$Y_{B}=7857.647 \mathrm{~m} ., X_{B}=5373.656 \mathrm{~m}$.

$\mathrm{Y}_{\mathrm{C}}=7865.622 \mathrm{~m} ., \mathrm{X}_{\mathrm{C}}=5374.284 \mathrm{~m}$.

$$
\begin{aligned}
& (\mathrm{AB})=200-\arctan \left(\frac{\mathbf{4 . 6 8 2}}{\mathbf{1 . 7 5 6}}\right)=122^{\mathrm{g}} .8430 \\
& (\mathrm{BC})=\arctan \left(\frac{\mathbf{7 . 9 7 5}}{\mathbf{0 . 6 2 8}}\right)=94^{\mathrm{g}} .9972
\end{aligned}
$$

The $\mathrm{AB}$ and $\mathrm{BC}$ chord lengths are obtained from the following equations (7) and (8).

$\mathrm{AB}=5.000 \mathrm{~m}$., $\mathrm{BC}=8.000 \mathrm{~m}$.

$\varphi=(\mathrm{BC})-(\mathrm{BA})+400=172^{\mathrm{g}} .1542$,

$\alpha_{1}=\arccos \left(\frac{2.5 * \sin \varphi}{\sqrt{\left[(2.5 * \cos \varphi-4)^{2}+(2.5 * \sin \varphi)^{2}\right]}}\right)=89^{\mathrm{g}} .3394$

$\alpha_{2}=\varphi-\alpha_{1}=82^{\mathrm{g}} .8148, \mathrm{R}=\frac{\mathbf{2 . 5}}{\cos \alpha 1}=14.999 \mathrm{~m} ., \mathrm{R}=\frac{\mathbf{4 . 0}}{\cos \alpha 2}$ $=14.999 \mathrm{~m} ., \mathrm{R}=15.00 \mathrm{~m}$.

The bearing angles from $\mathrm{A}, \mathrm{B}$ and $\mathrm{C}$ to the center $\mathrm{O}$ are obtained from the following equations.

$(\mathrm{AO})=(\mathrm{AB})-\alpha_{1}=46^{\mathrm{g}} .3169,(\mathrm{BO})=(\mathrm{BA})+\alpha_{1}-400=$ $12^{\mathrm{g}} .1824$

$(\mathrm{BO})=(\mathrm{BC})-\alpha_{2}=12^{\mathrm{g}} .1824,(\mathrm{CO})=(\mathrm{CB})+\alpha_{2}=377$ g.8120

Using the equations (21), (22) and (23), the coordinates of the center $\mathrm{O}$ are obtained as follows.

$\mathrm{A} \rightarrow \mathrm{Y}_{\mathrm{O}}=7860.499 \mathrm{~m} ., \mathrm{X}_{\mathrm{O}}=5388.382 \mathrm{~m}$.

$\mathrm{B} \rightarrow \mathrm{Y}_{\mathrm{O}}=7860.500 \mathrm{~m} ., \mathrm{X}_{\mathrm{O}}=5388.382 \mathrm{~m}$.

$\mathrm{C} \rightarrow \mathrm{Y}_{\mathrm{O}}=7860.500 \mathrm{~m}$., $\mathrm{X}_{\mathrm{O}}=5388.381 \mathrm{~m}$.

The exact coordinates of $\mathrm{O}: \mathrm{Y}_{\mathrm{O}}=7860.500 \mathrm{~m} ., \mathrm{X}_{\mathrm{O}}=$ $5388.382 \mathrm{~m}$.

\section{ALGORITHM FOR CALCULATION OF THE CENTER AND THE RADIUS}

1- Enter the stationary point number and coordinate $\left(\mathrm{P}_{1}\right.$, $\mathrm{YP}_{1}$, and $\mathrm{XP}_{1}$ )

2- Enter the starting point number and coordinate $\left(\mathrm{P}_{2}\right.$, $\mathrm{YP}_{2}$, and $\mathrm{XP}_{2}$ )
3- Enter Measured Horizontal Angles and Horizontal Lengths of the Points A, B and C Measured on the Circle Arch (BTA, BTB, BTC, SA, SB, SC) (Explanation: Horizontal Angles are $\beta_{A}=B$ BA, $\beta_{B}=B T B, \beta_{C}=B T C$. Horizontal Lengths are $\mathrm{SA}=\mathrm{S}_{\mathrm{A}}, \mathrm{SB}=\mathrm{S}_{\mathrm{B}}, \mathrm{SC}=\mathrm{SC}$ )

4- The $\left(\mathrm{P}_{1} \mathrm{P}_{2}\right)$ bearing angle is calculated based on the differences in the coordinates $\left(\Delta \mathrm{YP}_{1} \mathrm{P}_{2}\right.$ and $\left.\Delta \mathrm{XP}_{1} \mathrm{P}_{2}\right)$

$\Delta \mathrm{YP}_{1} \mathrm{P}_{2}=\mathrm{YP}_{2}-\mathrm{YP}_{1}$

$\triangle \mathrm{XP}_{1} \mathrm{P}_{2}=\mathrm{XP}_{2}-\mathrm{XP}_{1}$

The Bearing Angle Calculation Subprogram, by taking into account the expressions of $\Delta \mathrm{YP}_{1} \mathrm{P}_{2}, \Delta \mathrm{XP}_{1} \mathrm{P}_{2}$ and (P1P2), calculates the angle of the bearing angle in radian units and converts it to grad units.

5- Calculation of the bearing angles [(P1A), (P1B), (P1C)] for the points $\mathrm{A}, \mathrm{B}$ and $\mathrm{C}$ from the point $\mathrm{P}_{1}$ in grad and radian units;

Calculation of the bearing angles in grad units from the point $\mathrm{P}_{1}$ to the points $\mathrm{A}, \mathrm{B}, \mathrm{C}$

$\left(\mathrm{P}_{1} \mathrm{~A}\right)=\left(\mathrm{P}_{1} \mathrm{P}_{2}\right)-\mathrm{BTA}$

$\left(\mathrm{P}_{1} \mathrm{~B}\right)=\left(\mathrm{P}_{1} \mathrm{P}_{2}\right)-\mathrm{BTB}$

$\left(\mathrm{P}_{1} \mathrm{C}\right)=\left(\mathrm{P}_{1} \mathrm{P}_{2}\right)-\mathrm{BTC}$

$\rho=200 / \pi$

Conversion of the bearing angles into radians

$\left(\mathrm{P}_{1} \mathrm{~A}\right)=\left(\mathrm{P}_{1} \mathrm{~A}\right) / \rho$

$\left(\mathrm{P}_{1} \mathrm{~B}\right)=\left(\mathrm{P}_{1} \mathrm{~B}\right) / \rho$

$\left(\mathrm{P}_{1} \mathrm{C}\right)=\left(\mathrm{P}_{1} \mathrm{C}\right) / \rho$

6- Calculating the coordinates of the points $\mathrm{A}, \mathrm{B}$ and $\mathrm{C}$ from the point $\mathrm{P}_{1}$;

$\mathrm{YA}=\mathrm{YP}_{1}+\mathrm{SA} * \sin \left(\mathrm{P}_{1} \mathrm{~A}\right)$

$\mathrm{XA}=\mathrm{XP} 1+\mathrm{SA} * \cos \left(\mathrm{P}_{1} \mathrm{~A}\right)$

$\mathrm{YB}=\mathrm{YP}_{1}+\mathrm{SB} * \sin \left(\mathrm{P}_{1} \mathrm{~B}\right)$

$\mathrm{XB}=\mathrm{XP} 1+\mathrm{SB} * \cos \left(\mathrm{P}_{1} \mathrm{~B}\right)$

$\mathrm{YC}=\mathrm{YP}_{1}+\mathrm{SC} * \sin \left(\mathrm{P}_{1} \mathrm{C}\right)$

$\mathrm{XC}=\mathrm{XP}_{1}+\mathrm{SC} * \cos \left(\mathrm{P}_{1} \mathrm{C}\right)$

7-Calculating the angle of bearing (BC) and bearing (BA);

$\triangle \mathrm{YBC}=\mathrm{YC}-\mathrm{YB}$

$\triangle \mathrm{XBC}=\mathrm{XC}-\mathrm{XB}$

The subprogram for calculating the bearing, by taking into account the signs of $\triangle \mathrm{YBC}$ and $\triangle \mathrm{XBC}$, calculates the angle of the bearing (BC) in radian units and converts it to grad units.

$\triangle \mathrm{YBA}=\mathrm{YA}-\mathrm{YB}$

$\triangle \mathrm{XBA}=\mathrm{XA}-\mathrm{XB}$

The subprogram for calculating the bearing, by taking into account the signs of $\triangle \mathrm{YBA}$ and $\triangle \mathrm{XBA}$, calculates the angle of the bearing (BA) in radian units and converts it to grad units. 
8- Calculation of the chord lengths BA and BC;

$$
\begin{aligned}
& \mathrm{BA}=\sqrt{\left(\left(\Delta \mathbf{Y B A}^{2}\right)+\left(\Delta \mathbf{X B A}^{2}\right)\right)} \\
& \mathrm{BC}=\sqrt{\left(\left(\Delta \mathbf{Y B C}^{2}\right)+\left(\Delta \mathbf{X B C}^{2}\right)\right)}
\end{aligned}
$$

9- Comparison of the $\mathrm{BA}$ and $\mathrm{BC}$ chord lengths

If $\mathrm{BA}=\mathrm{BC}$ go to step 10

If $\mathrm{BA} \neq \mathrm{BC}$ go to step 14

10- Calculation of base angles and $\mathrm{R}$ values of triangles $\alpha=((\mathrm{BC})-(\mathrm{BA})) / 2$

Conversion of $\alpha$ to radian units

$\alpha=\alpha / \rho$

$\varepsilon=\pi-2 \alpha$

Calculation of $\mathrm{R}, \mathrm{AO}, \mathrm{BO}$ and average $\mathrm{R}$

$\mathrm{R}=\mathrm{AO}=\mathrm{BO}$

$\mathrm{AO}=\mathrm{AB} * \sin \alpha / \sin \varepsilon$

$\mathrm{BO}=\mathrm{BC} * \sin \alpha / \sin \varepsilon$

$\mathrm{R}=(\mathrm{AO}+\mathrm{BO}) / 2$

Conversion of the (BA) and $(\mathrm{BC})$ bearing angles to radian units

$(\mathrm{BA})=(\mathrm{BA}) / \rho$

$(\mathrm{BC})=(\mathrm{BC}) / \rho$

11- Calculation of the bearing angles [(BO1), (AO), (BO2), (CO)] from the points $\mathrm{A}, \mathrm{B}$ and $\mathrm{C}$ points to the center of the circle

$(\mathrm{BO} 1)=(\mathrm{BA})-\alpha$

If $(B A)>\pi$ then $(A B)=(B A)-\pi$

If $(B A)<\pi$ then $(A B)=(B A)+\pi$

$(\mathrm{AO})=(\mathrm{AB})-\alpha$

$(\mathrm{BO} 2)=(\mathrm{BC})-\alpha$

If $(\mathrm{BC})>\pi$ then $(\mathrm{CB})=(\mathrm{BC})-\pi$

If $(\mathrm{BC})<\pi$ then $(\mathrm{CB})=(\mathrm{BC})+\pi$

$(\mathrm{CO})=(\mathrm{CB})+\alpha$

12- Calculating the coordinates of the center of the circle from the points $\mathrm{A}, \mathrm{B}$ and $\mathrm{C}$;

$\mathrm{YOA}=\mathrm{YA}+\mathrm{R} * \sin (\mathrm{AO})$

$\mathrm{XOA}=\mathrm{XA}+\mathrm{R} * \cos (\mathrm{AO})$

$\mathrm{YOB}=\mathrm{YB}+\mathrm{R} * \sin (\mathrm{BO})$

$\mathrm{XOB}=\mathrm{XB}+\mathrm{R} * \cos (\mathrm{BO})$

$\mathrm{YOC}=\mathrm{YC}+\mathrm{R} * \sin (\mathrm{CO})$

$\mathrm{XOC}=\mathrm{XC}+\mathrm{R} * \cos (\mathrm{CO})$

13- Printing the radius $\mathrm{R}$ of the circle and the coordinates of the center $\mathrm{O}$

14- Calculation of the angle $\varphi$ between the chords BA and $\mathrm{BC}$ cat the point $\mathrm{B}$ and the values $\mathrm{a}$ and $\mathrm{b}$

$\varphi=(\mathrm{BC})-(\mathrm{BA})$

$\varphi=\varphi / \rho$

$\mathrm{a}=\mathrm{AB} / 2$

$\mathrm{b}=\mathrm{BC} / 2$

15- Calculation of the base angles $\left(\alpha_{1}, \alpha_{2}\right)$ of triangles and $\mathrm{R}$;

$\alpha_{1}=\arccos \left(\mathrm{a} * \sin \varphi / \sqrt{\left((\operatorname{acos} \varphi-\boldsymbol{b})^{2}+(\boldsymbol{a s i n} \varphi)^{2}\right)}\right)$

$\alpha_{2}=\varphi-\alpha_{1}$

$\mathrm{R}_{1}=\mathrm{a} / \cos \alpha_{1}$

$\mathrm{R}_{2}=\mathrm{b} / \cos \alpha_{2}$

$\mathrm{R}=\left(\mathrm{R}_{1}+\mathrm{R}_{2}\right) / 2$
16- The points $\mathrm{A}, \mathrm{B}$ and $\mathrm{C}$ from the center of the circle for the calculation of the angle;

$\left(\mathrm{BO}_{1}\right)=(\mathrm{BA})+\alpha_{1}$

If $(\mathrm{BA})>\pi$ then $(\mathrm{AB})=(\mathrm{BA})-\pi$

If $(\mathrm{BA})<\pi$ then $(\mathrm{AB})=(\mathrm{BA})+\pi$

$(\mathrm{AO})=(\mathrm{AB})-\alpha_{1}$

$(\mathrm{BO} 2)=(\mathrm{BC})-\alpha_{2}$

If $(\mathrm{BC})>\pi$ then $(\mathrm{CB})=(\mathrm{BC})-\pi$

If $(\mathrm{BC})<\pi$ than $(\mathrm{CB})=(\mathrm{BC})+\pi$

$(\mathrm{CO})=(\mathrm{CB})+\alpha_{2}$

17- Go to step 13 to calculate the coordinates of the center of the circle at the points $\mathrm{A}, \mathrm{B}$ and $\mathrm{C}$.

\section{DISCUSSION}

(1), (10) and (11) in the case of zero in the case of division; In equation (1), XP1 = XP2, in equation (10), $\mathrm{XB}=\mathrm{XC}$ and (11) must be $\mathrm{XB}=\mathrm{XA}$. The equation (1) can be XP1 $=$ XP2. However, considering that the points $\mathrm{A}, \mathrm{B}, \mathrm{C}$ are on the circle arc, it is not possible to have $\mathrm{XB}$ $=\mathrm{XC}, \mathrm{XB}=\mathrm{XA}$. The results of equations (21), (22) and (23) must be equal to each other.

However, due to incidental errors that cannot be avoided during measurement, there may be little differences in $\mathrm{cm}$ units in the calculated coordinate results. In this case, it would be more appropriate to obtain the average of the results gathered from the equations. In cartography, one tenth of the circle radius is taken as the best distance between the points to be applied on the circle arc.

In determining the center, the distance to be taken between the points to be marked on the circle arc should be carefully selected to not be less than one tenth of the circle radius length. If a point is taken in a range smaller than the specified value, the lines connecting these points to the center $\mathrm{O}$ of the circle intersect at a very narrow angle. This will negatively affect the position accuracy of the point $\mathrm{O}$.

More than three points can be taken on the circle arc. In this case, the coordinate of the center and the length of the radius, will be calculated with the least squares method according to the adjustment calculation.

The positioning of the three points on the circle can be achieved in two ways, as stated in the article. In the first method, the points are positioned on the circle so that they are of equal beam length. In the second method, the points are positioned at different beam lengths. For ease of calculation, it is recommended to position the points on the circle according to the first method.

\section{CONCLUSIONS}

- The length of a chord and the horizontal distances to be measured to determine the radius and center coordinates of a circular pool of unknown radii; measurements should be made in millimetric precision for control and consistency of results.

- In measurements to determine the radius of a building with a radius of unknown radius and the coordinates of its center; a) The reflector 
used to measure the sharpness of the reflector head will not be exactly perpendicular to the projection of the building due to the thickness of the head, b) the distance from the building line to the pointed end of the reflector should be added to the horizontal distance measured with the aid of a ruler in millimetric precision.

- Where the chord length is directly measured, the equal chord length method should be applied in the calculation of the circle radius and the circle center coordinate, because of the ease of calculation.

- Where the chord length cannot be measured directly, three points on the circle arc should be marked very precisely so as to cover half the circumference of the entire circle.

- At places where the beam length cannot be measured directly, at least three separate points should be marked very precisely on the arc of the circle to cover half of the circumference of the entire circle and for control purposes.

- The reflector used in polar measurements must be as sharp as possible in the tip that comes into contact with the floor.

On the subject of the Type Reconstruction Regulation;

- Width of road in 3-storey buildings (excluding basement): $7.00-10.00 \mathrm{~m}$

- Width of road in 4-storey buildings (excluding basement): $10.00-12.00 \mathrm{~m}$.

- Width of road in 5-storey buildings (excluding basement): $12.00-15.00 \mathrm{~m}$, this cannot be less, and provisions are included.

\section{REFERENCES}

Allan, A.L., Hollwey, J.R., and Maynes, J.H.B. 1968. Practical Field Surveying and Computations. Heinnemann, London.

Anderson, J.M. and Mikhail, E.M., 1998. Surveying theory and practice. 7th ed. Boston, MA: Mc Graw Hill.

Bannister, A., Baker, R., and Raymond, S., 1992. Surveying. John Willey \& Sons. Inc., New York, pp. 186-188.
Bannister, A., Raymond, S. and Baker, R., 1998. Surveying. 7th ed. Harlow, UK: Addison Wesley Longman Limited Edinburg Gate, 81-82.

Coope, I. D. , 1993. Circle fitting by linear and nonlinear least squares. Journal of Optimization Theory and Applications, 76(2), 381-388.

Erdem, N., and İnce, H., 2016. The Proposal Of The Building Application For More Benefiting From Solar Light, International Journal of Engineering and Geosciences, 1 (1), 7-14. DOI: 10.26833/ijeg.285215

İnce, H, Erdem, N., 2019. Positioning Buildings on a Zoning Island to Provide Maximum Shading: A Case Study. International Journal of Engineering and Geosciences, 4 (3), 129-140. DOI: 10.26833/ijeg.525020

Kåsa, I., 1976. A circle fitting procedure and its error analysis. IEEE Transactions on instrumentation and measurement, (1), 8-14.

Kavanagh, F. B., 2003. Geomatics. Pearson Education 'Inc. Prentice Hall, Upper Saddle River, NJ pp. 159-160.

Kavanagh, F. B., and Bird, S.J.G., 2000. Surveying Principles and Applications. Pearson Education Inc. Prentice Hall, Upper Saddle River, NJ

Kavanagh, F.B., 2009. Surveying principles and application. 8th ed. Columbus: Pearson Education Inc., 525-526.

Ulvi, A , Toprak, A., 2016. Investigation of ThreeDimensional Modelling Availability Taken Photograph of the Unmanned Aerial Vehicle; Sample of Kanlidivane Church. International Journal of Engineering and Geosciences, 1 (1), 1-7. DOI: 10.26833/ijeg.285216

Wilfred, S., 2001. Engineering surveying. 5th ed. Oxford, UK: Butterworth Heinemann, 395-397.

Wolf, P. R., and Ghilani, C. D., 2008. Elementary Surveying an Introduction to Geomatics. 12th Edition, Upper Saddle River, New Jersey: Pearson Prentice-Hall. pp 271-274, 716-717, 720-721 